\title{
Corrosion Experimental Research on Local Damage of Epoxy-Coated Steel Bars in Concrete Under Marine Environment
}

\author{
Hongfei Cao ${ }^{1,2 *}$, Zhongda $\mathrm{Lyu}^{2,3 *}$, Wei Dong ${ }^{4,5}$, Zhuo Zhao ${ }^{2,3}$, Weizhong Gan $^{2,3}$ and \\ Yonggang Wang ${ }^{1}$
}

${ }^{1}$ Faculty of Mechanical Engineering and Mechanics, Ningbo University, Ningbo, China, ${ }^{2}$ School of Civil and Transportation Engineering, Ningbo University of Technology, Ningbo, China, ${ }^{3}$ Engineering Research Center of Industrial Construction in Civil Engineering of Zhejiang, Ningbo University of Technology, Ningbo, China, ${ }^{4}$ China Highway Engineering Consulting Corporation, Road and Bridge Design and Research Institute Branch, Wuhan, China, ${ }^{5}$ School of Highway, Chang'an University, Xi'an, China

OPEN ACCESS

Edited by:

Zhigang Zhang,

Chongqing University, China

Reviewed by:

Fengjiang Qin,

Chongqing University, China

Yang Zou,

Chongqing Jiaotong University, China

*Correspondence: Hongfei Cao caohongfei92@163.com Zhongda Lyu Izd01@189.cn

Specialty section: This article was submitted to Structural Materials, a section of the journal Frontiers in Materials

Received: 24 November 2021 Accepted: 15 December 2021 Published: 26 January 2022

Citation:

Cao H, Lyu Z, Dong W, Zhao Z, Gan W and Wang $Y$ (2022) Corrosion

Experimental Research on Local Damage of Epoxy-Coated Steel Bars in Concrete Under Marine Environment.

Front. Mater. 8:821716.

doi: 10.3389/fmats.2021.821716
Epoxy coating has been proven to protect steel bars from corrosion. However, the damage of epoxy coating is inevitable, and this may lead to more serious corrosion of steel bar. In order to study the corrosion resistance of steel bars with damaged epoxy coating, two groups of coating-damaged bar and one group of coating-intact rebar were designed, and six specimens were made. The influence of electrolyte concentration on the corrosion rate of steel bars was studied by setting different concentrations. After 30 days of accelerated corrosion, electrochemical data were recorded by the electrochemical workstation. The experimental result shows that the steel bars with coating damage have obvious polarization curve characteristics of corrosion, and corrosion resistance decreases obviously. According to the corrosion current and potential, the larger the damaged area of the coating, the faster will be the corrosion rate. According to the polarization curve data, the polarization resistance is modified, and the result is closer to the real polarization resistance value. The calculated corrosion rate shows that the corrosion rate of reinforcement is affected by both electrolyte concentration and coating damage area, and electrolyte concentration has a greater influence on the corrosion rate.

Keywords: corrosion, epoxy-coated steel bar, accelerated corrosion, linear polarization, marine environment

\section{INTRODUCTION}

As the bridge is gradually extended to the deep sea, the bridge not only needs to bear more complex loads but also will meet more severe durability problems of concrete structures. The mechanical failure of the concrete structure usually begins with material failure. For deepwater structures, corrosion, crack, breakage, and other problems of basic materials will lead to attenuation of structural resistance and affect the long-term bearing capacity, service safety, and reliability of the structure.

Additional measures on existing structures can reduce the probability of corrosion, such as coating concrete surfaces, corrosion inhibitors, electrochemical dechlorination, cathodic protection, high corrosion-resistant steel materials, and various coated steel bars. Because of its convenience, reinforcement-protective coating has been used in engineering (Stratmann et al., 1994; Grundmeier et al., 2000). In order to study the effectiveness of epoxy-coated steel bars, many 
TABLE 1 | Parameters of test block.

\begin{tabular}{|c|c|c|c|c|}
\hline Concrete strength grade & $\begin{array}{l}\text { Size of test block } \\
(\mathrm{cm})\end{array}$ & $\begin{array}{c}\text { Concentration of } \mathrm{NaCl} \\
\text { solution }\end{array}$ & & Epoxy-coated steel bars (HRB400) \\
\hline \multirow[t]{6}{*}{ C40 } & $15^{\star} 15^{\star} 30$ & $0.1 \mathrm{~mol} / \mathrm{L}$ & S1 & Without damage \\
\hline & & & S2 & The damaged area was $0.5 \mathrm{~cm}^{2}$, and the length of damage was $2 \mathrm{~cm}$ \\
\hline & & & S3 & The damaged area was $1 \mathrm{~cm}^{2}$, and the length of damage was $4 \mathrm{~cm}$ \\
\hline & & $1 \mathrm{~mol} / \mathrm{L}$ & S4 & Without damage \\
\hline & & & S5 & The damaged area was $0.5 \mathrm{~cm}^{2}$, and the length of damage was $2 \mathrm{~cm}$ \\
\hline & & & S6 & The damaged area was $1 \mathrm{~cm}^{2}$, and the length of damage was $4 \mathrm{~cm}$ \\
\hline
\end{tabular}

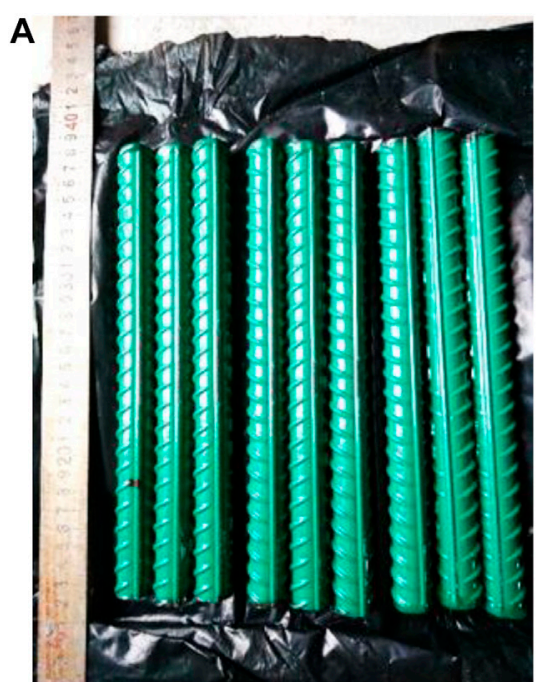

Steel bar coated with epoxy coating
B

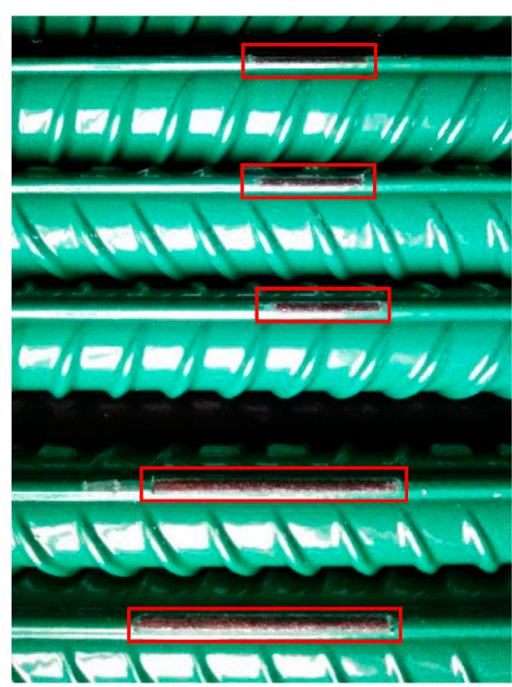

Damaged epoxy-coated steel bar

FIGURE 1 | Epoxy-coated steel bar specimen. (A) Steel bar coated with epoxy.

(B) Damaged epoxy-coated steel bar.

corrosion experiments and investigations had been carried out (Atilgan et al., 2018; Clear et al., 1995; Smith and Virmani, 1996; Manning, 1996; Weyers et al., 1997; Pyc', 1998; Montes et al., 2004; Venkatesan et al., 2006). The effectiveness of epoxy-coated steel bars was verified. However, some studies only considered the influence of environmental factors, ignoring the influence of construction quality, integrity of epoxy coating, and other factors, so the effect of epoxy coating could not be accurately analyzed.

Through the experiment and technical improvement, the protection performance of epoxy coating on steel bars has been continuously improved (Nguyen and Martin, 2004; Singh and Ghosh, 2005; Selvaraj et al., 2009; Caldona et al., 2021). By changing the material and structure of the coating, the integrality performance of the reinforced concrete structure which is composed of epoxy-coated steel bars, and concrete has been verified and improved (Kim and Andrawes, 2019; Zhang et al., 2020; Shang et al., 2021). Epoxy coating can provide protection for steel bars even in the case of poor concrete quality (Darwin and Scantlebury, 2002). The corrosion protection of steel bars depends on the integrity of the epoxy coating, and its protection is always suspected once the epoxy coating is damaged (Manning,
1996; Darwin and Scantlebury, 2002; Kobayashi and Takewaka, 1984; Bautista and González, 1996; Gowripalan and Mohamed, 1998; Bellezze et al., 2006; Erdogudu et al., 2001). The damage of epoxy coating may be caused by many reasons, such as bumping during construction and transportation, structural deformation, damage during use, and chemical reaction with surrounding substances (Wang et al., 2015; Wang and Gao, 2016; Zhao et al., 2021). Corrosion may not occur in the short term due to the alkaline environmental protection provided by concrete (Bellezze et al., 2006), but its long-term performance may have a great impact (Elleithy et al., 1998).

In this study, the corrosion electrochemical characteristics of epoxy rebars with damaged surface coating are studied. In order to speed up the process of the experiment, the impressed current (IC) technique was used to accelerate the corrosion of steel bsar (Li et al., 2021). Six epoxy-coated rebar specimens were manufactured with different degrees of breakage and placed in $\mathrm{NaCl}$ solution to simulate corrosion under the marine environment. The corrosion of epoxy-coated rebars was tested using the linear polarization method. According to the obtained electrochemical parameters, the corrosion of steel bars was quantitatively analyzed, and the influence of coating damage 

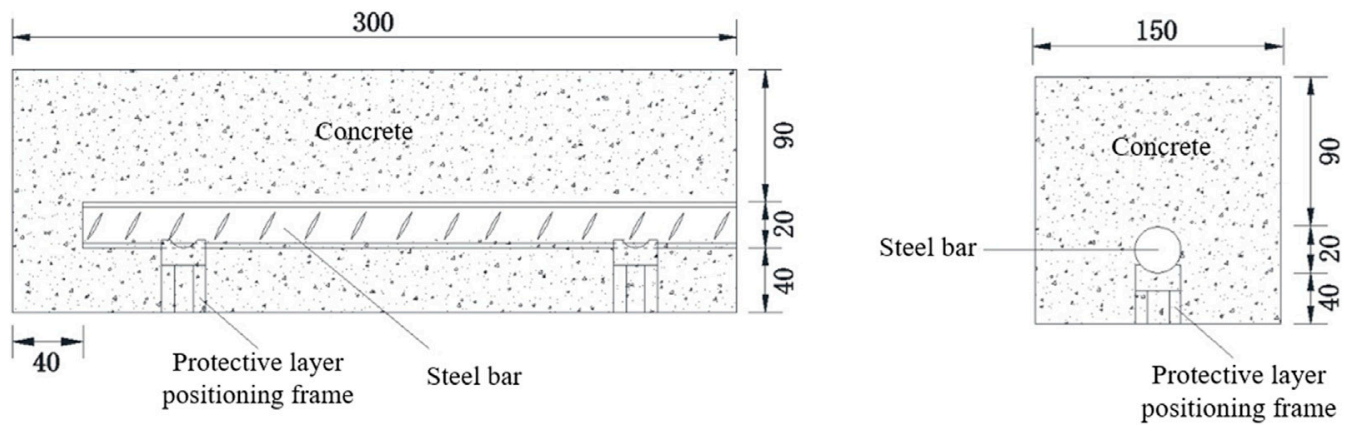

FIGURE 2 | Layout of epoxy-coated steel bar.

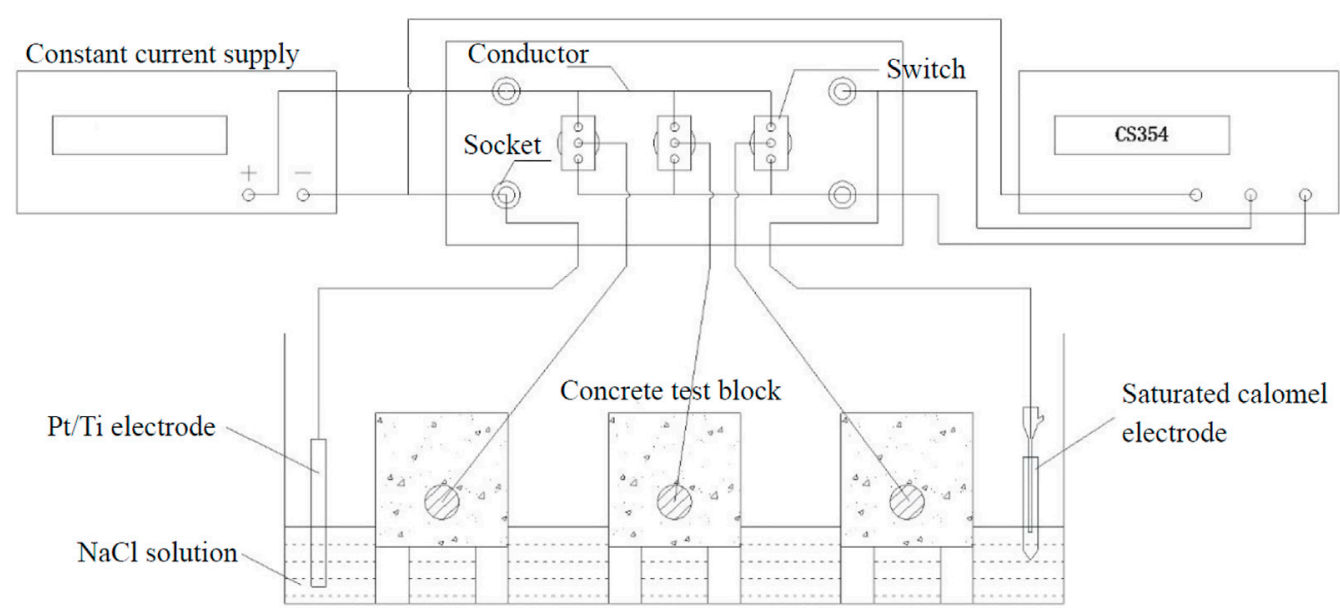

FIGURE 3 | Schematic diagram of the experimental device.

on steel bar corrosion could be obtained. The research results of this study could provide theoretical support for the application of epoxy-coated steel bars under the marine environment.

\section{EXPERIMENTAL DESIGN}

\section{Specimen Design}

In this experiment, the influence of different damage degrees of epoxy coating on steel bars corrosion was mainly considered. Therefore, three groups of concrete blocks containing epoxycoated steel bars with different damage levels were designed. Table 1 summarizes the design parameter details of the tested epoxy-coated steel bars and blocks.

The epoxy-coated steel bar was an HRB400 steel bar with a diameter of $20 \mathrm{~mm}$. The specimen of steel bar was cut to $26 \mathrm{~mm}$ in length. The epoxy coating was a Valspar product. After blending the coating and curing agent in a ratio of 5:1, epoxy was evenly coated on the surface of the steel bar. To simulate the damage of the epoxy rebar, part of the coating from the surface of the steel bar was removed with a file (Figure 1). The protective layer positioning frame was secured to the steel bar, and the uncoated end of the steel bar was attached to the die in order to connect the wires (Figure 2). After connecting the wire, the exposed steel bar at the end was sealed with epoxy adhesive.

\section{Experimental Apparatus}

The experimental apparatus was mainly composed of four parts, as shown in Figure 3.

(1) Current stable supply: This part was mainly composed of single-channel adjustable DC power supply and external wire.

(2) Switch box (Figure 4): The constant current power supply and the CS354 electrochemical workstation were connected to the switch box through a socket, so the test process could be controlled through the switch. By flipping the switch on the switch box, the corrosion of the steel bar could be accelerated, and the electrochemical information such as resistance and potential of the steel bar in the sample 
A

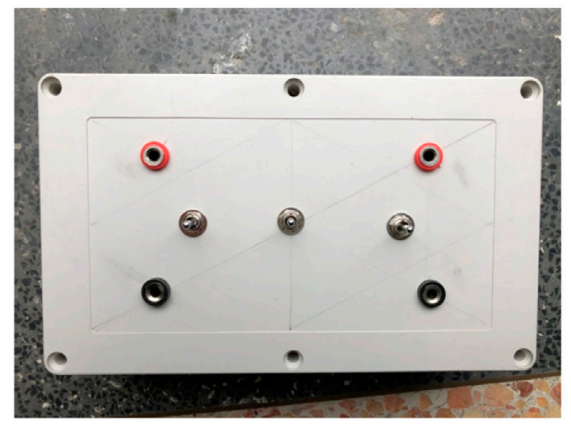

B

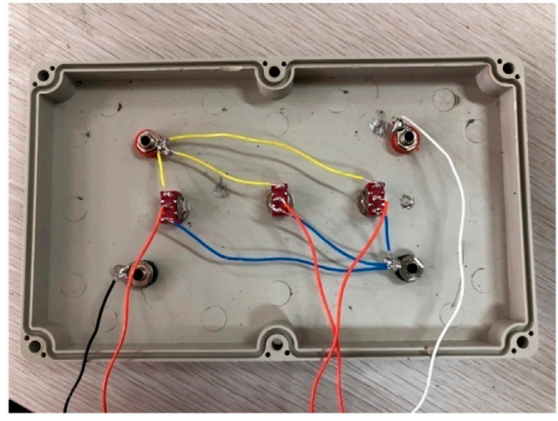

FIGURE 4 | Switch box. (A) Surface of the switch box. (B) Inside of the switch box.

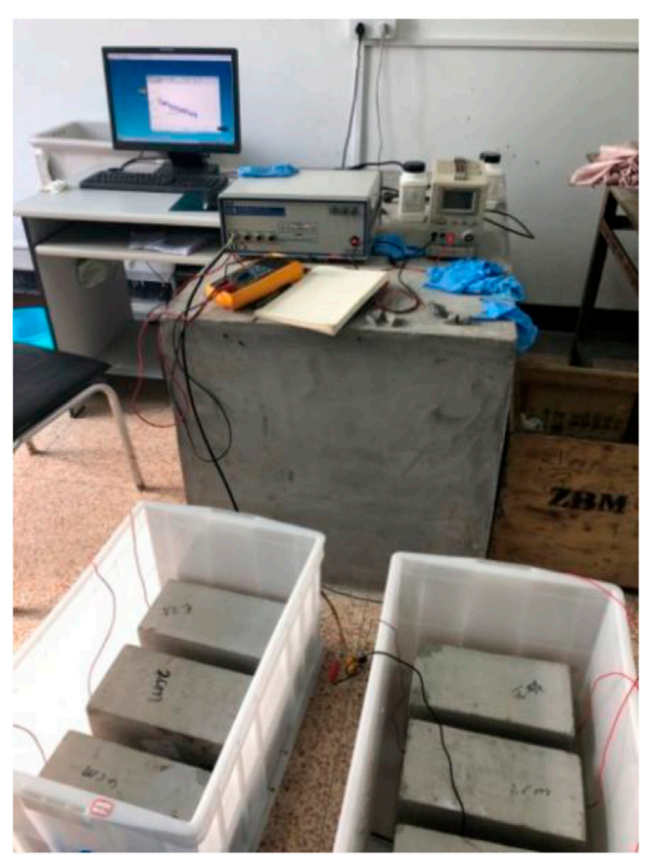

FIGURE 5 | Accelerated corrosion method and measurement of electric polarization parameter.

could be measured. By using this equipment, the artificial test error caused by multiple measurements was reduced.

(3) The CS354 electrochemical workstation: This part was mainly composed of workstations and external wires. The CS354 electrochemical workstation could complete electrodynamic potential or dynamic current scanning, electrochemical impedance spectroscopy, and other electrochemical testing functions, which could meet the requirements of this test (Guan, 2007).

(4) Specimen test box: This part was composed of concrete test blocks, saturated calomel electrode, $\mathrm{Pt} / \mathrm{Ti}$ electrode, $\mathrm{NaCl}$ solution, platinum cathode electrode, and conductors. Concrete test blocks were padded with wooden blocks and shelved in test boxes. A certain amount of $\mathrm{NaCl}$ solution was poured into the test box, and the reference electrode and platinum electrode were placed in $\mathrm{NaCl}$ solution. $\mathrm{NaCl}$ solution was used as a corrosion medium to simulate the marine environment.

\section{Experimental Process}

Due to the protection of concrete and epoxy coating, the corrosion rate of the steel bar under natural conditions is slow. In order to speed up the process of the experiment, the electrochemical accelerated corrosion method was used to accelerate the corrosion rate of the steel bar. In order to avoid the obvious error between the corrosion caused by accelerated corrosion and the corrosion results produced in the natural environment due to excessive current density, the recommended critical value of $2000 \mu \mathrm{A} / \mathrm{cm}^{2}$ was used in this experiment ( $\mathrm{Wu}, 2016$; Feng et al., 2021). The steel bar in each concrete test block was connected to the switch box in parallel. It was calculated that the current provided to the steel bar block should be about $28.84 \mathrm{~mA}$, so the output current of this experiment was set to $30 \mathrm{~mA}$.

The current stable supply was connected to the switch box, and then the power supply was switched on to start galvanizing corrosion and control the galvanizing time and current size, as shown in Figure 5. The polarization curves were measured in different time periods, and the corrosion rates of steel bars at the damaged parts of the coating were calculated.

\section{RESULT AND DISCUSSION}

\section{Analysis of Polarization Curve}

After accelerated corrosion of each test block, the polarization curves of the specimens at different times were measured and plotted, as shown in Figure 6. As can be seen from the polarization curve in Figure 6A, the polarization curve slope of the epoxy steel bar with no surface damage in the test block after electrochemical accelerated corrosion is very large, without typical polarization curve characteristics, showing obvious low corrosion characteristics. In Figure 6B, after accelerated corrosion lasts for 30 days, corrosion current appears in the circuit, indicating that corrosion begins to occur in the epoxy steel bar. The cause may be slight damage to the epoxy coating 


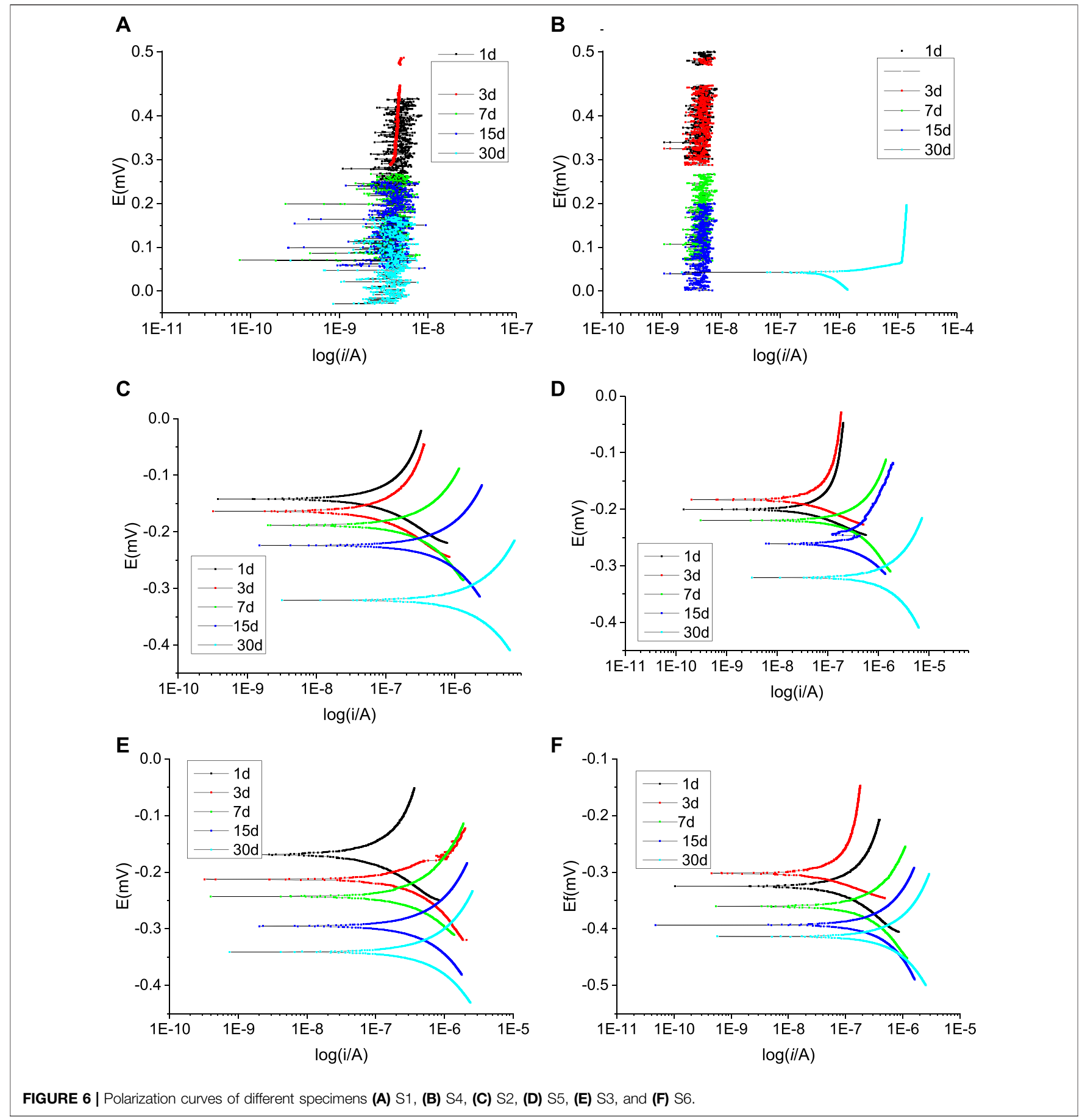

when assembling the specimen or pouring the concrete, resulting in a weak current in the circuit.

As can be seen from the polarization curves in Figure $6 \mathrm{C}$, the steel bars show obvious corrosion characteristics. With the development of corrosion, the polarization curves gradually move to the lower right direction, that is, the corrosion rate $\left(\mathrm{I}_{\text {corr }}\right)$ increases and the corrosion potential $\left(\mathrm{E}_{\mathrm{corr}}\right)$ decreases. Since the damage length of coating is relatively small, the change in polarization current in the system has a greater impact on corrosion. As can be seen from Figure 6D, compared with the electrolyte solution of $0.1 \mathrm{~mol} / \mathrm{L}$, the polarization curve of the anode rises faster. The increase in electrolyte concentration promotes the corrosion of steel bars, accelerates the activation state of epoxy steel bars with damaged surfaces in concrete specimens, and accelerates the corrosion reaction. 

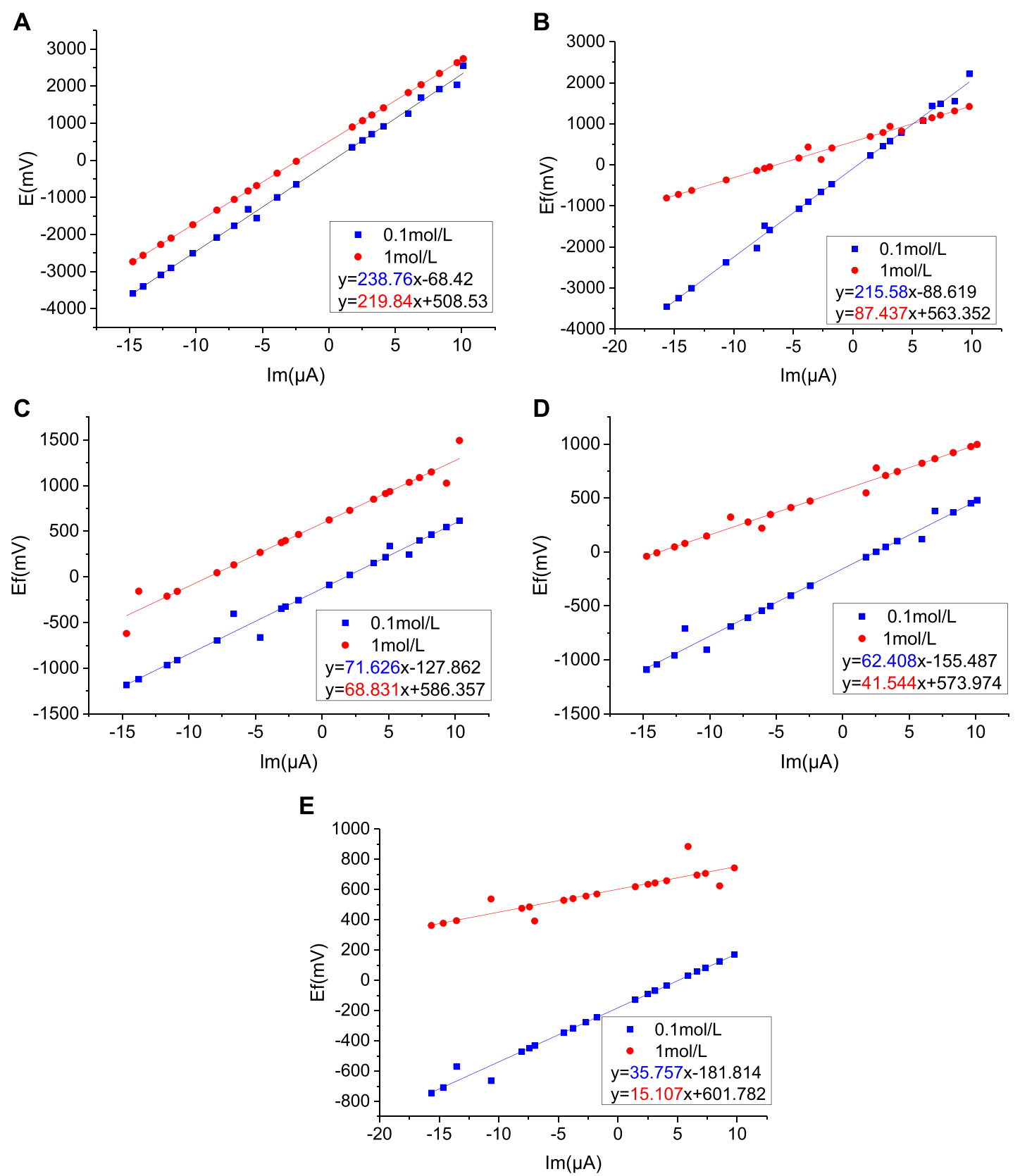

FIGURE 7 | Fitted polarization resistance of S2 and S5 at different times (A) 1d, (B) 3d, (C) 7d, (D) 15d, and (E) 30d.

Figure 6F shows the polarization curve of the steel bar at different corrosion times when the concentration of $\mathrm{NaCl}$ solution is $1 \mathrm{~mol} / \mathrm{L}$, and the surface coating is damaged by $4 \mathrm{~cm}$. Compared with the case of coating damage of $2 \mathrm{~cm}$ under the same other conditions, the increase in the anodic polarization curve in this part is slower, indicating that the self-corrosion current $\left(\mathrm{I}_{\text {corr }}\right)$ is higher and the self-corrosion potential $\left(\mathrm{E}_{\text {corr }}\right)$ is lower after changing this parameter.

The polarization curve of the epoxy steel bar varies according to the degree of corrosion. Generally speaking, if the electrode is polarized from the cathode to the anode, the equilibrium potential of the polarization curve will move in the negative direction. If the steel bar is passivated, the offset increases significantly. As shown in Figure 6, the cathode polarization curves are very stable on the third day. However, the anode polarization curves rise rapidly, and the Tafel slope is very large. The anode reaction process is very difficult. Based on the principle of corrosion potential, it can be known that the steel bar in the damaged area of the coating may be passivated. 

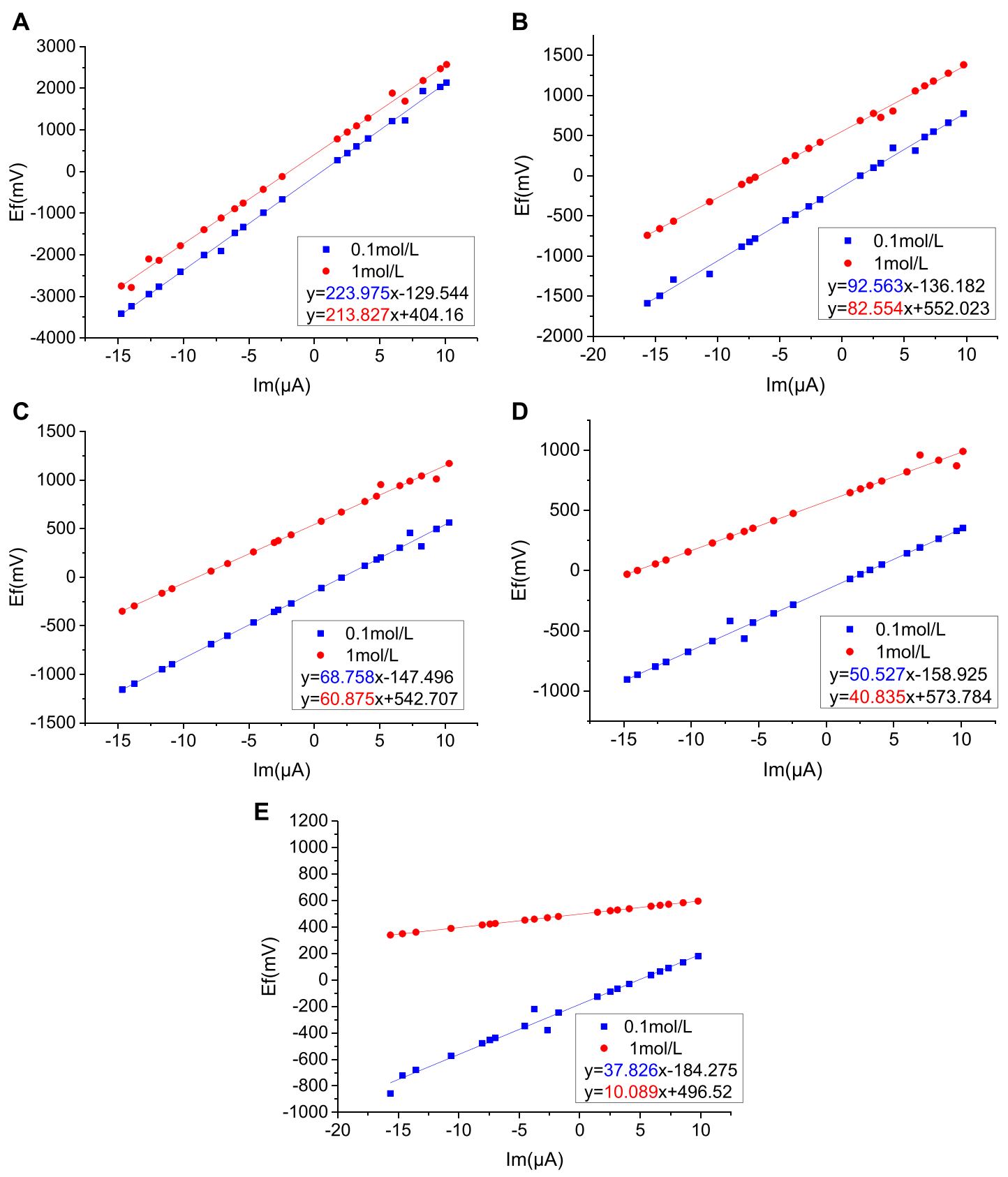

FIGURE 8 | Fitted polarization resistance of S3 and S6 at different times (A) 1d, (B) 3d, (C) 7d, (D) 15d, and (E) 30d.

With the development of corrosion, the range of negative and anode zone becomes smaller, indicating that the passivation state of the steel bar is not stable. The aforementioned phenomenon shows that the pitting resistance of epoxy-coated steel bars is getting weaker. It can be seen from Figure 6E that the partial area of the anode showed fluctuations, which may be due to the microcracks on the surface of the epoxy-coated steel bar and then repassivation. Then the passivation layer broke again under the action of the corrosion solution, resulting in the fluctuation of the corrosion current.
After 30 days of accelerated corrosion, the polarization curve of the anode becomes more stable and $\beta_{a}$ becomes smaller. It can be seen that the reaction of the anode is good, and the steel bar at the damaged site is highly involved in the reaction.

As can be seen from the characteristics of the polarization curve, the steel bar appears passivated on the third day, while the passivation film gradually disappears on the seventh day. With the concentration of $\mathrm{NaCl}$ solution is $1 \mathrm{~mol} / \mathrm{L}, \beta_{a}$ of the anodic curve of the steel bar with damaged surface coating goes to infinity on the third day of corrosion, indicating that a dense 


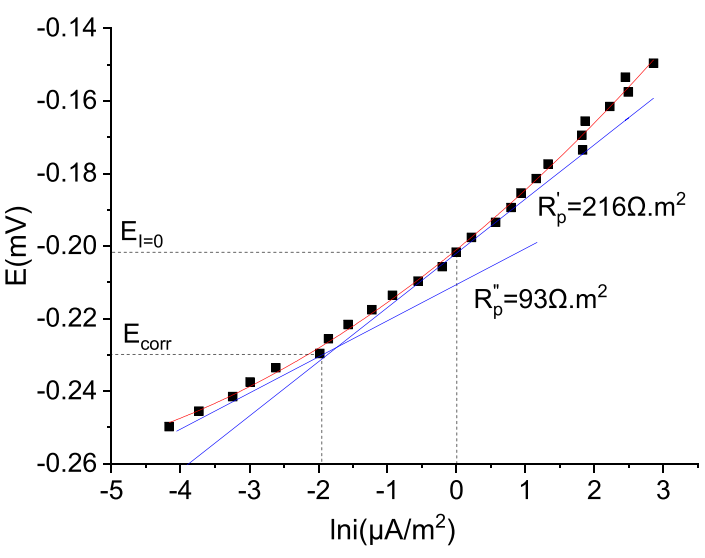

FIGURE 9 | Polarization curves of feature points.

TABLE 2 | Effect of scanning rate on potential offset.

\begin{tabular}{lcccc} 
Scanning rate $(\mathbf{m V} / \mathbf{s})$ & $\boldsymbol{R}_{\boldsymbol{p}}^{\prime}\left(\boldsymbol{\Omega} \cdot \mathbf{m}^{\mathbf{2}}\right)$ & $\boldsymbol{R}_{\boldsymbol{p}}^{\prime \prime}\left(\boldsymbol{\Omega} \cdot \mathbf{m}^{\mathbf{2}}\right)$ & $\boldsymbol{R}_{\boldsymbol{p}}^{\prime} / \boldsymbol{R}_{\boldsymbol{p}}^{\prime \prime}$ & $\boldsymbol{E}_{\text {corr }}-\boldsymbol{E}_{\boldsymbol{I = 0} \mathbf{0}}(\mathbf{m V})$ \\
\hline 0.10 & 268 & 298 & 0.90 & 2.7 \\
0.25 & 127 & 184 & 0.69 & 3.8 \\
0.50 & 20 & 37 & 0.55 & 4.2 \\
\hline
\end{tabular}

passivation layer has been formed on the surface. At this time, the polarization current is mainly controlled by the cathode reaction.

\section{Corrosion Potential}

Figures $6 \mathrm{~A}, \mathrm{~B}$ show the corrosion potential $\mathrm{E}_{\text {corr }}$ of the epoxy steel bar without surface damage maintained at about $0.25 \mathrm{mV}$ after the accelerated corrosion test. It shows that the probability of steel bar corrosion is low. For epoxy steel bars without surface damage, 30 days of accelerated corrosion do not increase the risk of corrosion. For damaged steel bars, according to the change in corrosion potential, it can be seen that the corrosion of steel bars has been developing, and the corrosion potential continues to decrease.

By comparing the corrosion potential in different concentrations of the solution, it can be seen that the higher the concentration of the solution, the greater the negative value of corrosion potential. In addition, at the same electrolyte concentration, the greater the damage degree of epoxy coating, the faster will be the corrosion rate.

The disturbance of the electrode is excluded, and the effect of the ion diffusion rate on the electrode reaction is considered. With the progress of corrosion, $\mathrm{Cl}^{-}$in the coat-damaged area of the steel bar gradually accumulates, and the reaction rate of the anode area is faster and faster. When the $\mathrm{O}_{2}$ diffusion rate of the anode region is less than the corrosion reaction rate, the reaction rate of the anode is mainly determined by the $\mathrm{O}_{2}$ diffusion rate.

TABLE 3 | Analysis of the anode polarization curve.

\begin{tabular}{|c|c|c|c|c|c|}
\hline$T / d$ & $\omega(\mathrm{NaCl}) /(\mathrm{mol} / \mathrm{L})$ & $\mathrm{d} / \mathrm{cm}$ & $\bar{R}_{p} /\left(\Omega \bullet \mathrm{cm}^{2}\right)$ & $\bar{i}_{\text {corr }}\left(\mathrm{mA} / \mathrm{cm}^{2}\right)$ & $\bar{V}_{\text {corr }}(\mathrm{mm} / \mathrm{a})$ \\
\hline & & 2 & 238,760 & 7.46E-05 & 7.34E-04 \\
\hline & 1 & 0 & 756,681 & 1.02E-06 & 1.01E-05 \\
\hline & & 2 & 219,840 & 8.27E-05 & 8.13E-04 \\
\hline & & 4 & 213,827 & 8.36E-05 & 8.22E-04 \\
\hline & & 4 & 92,563 & 1.74E-04 & 1.71E-03 \\
\hline & 1 & 0 & 534,289 & 5.87E-06 & 5.45E-05 \\
\hline & & 2 & 387,437 & 1.93E-05 & 1.90E-05 \\
\hline & & 4 & 382,554 & 1.96E-05 & $1.92 \mathrm{E}-05$ \\
\hline \multirow[t]{2}{*}{7} & 0.1 & 0 & 427,320 & 4.15E-05 & 4.08E-04 \\
\hline & & 2 & 71,626 & 2.38E-04 & 2.34E-03 \\
\hline \multirow[t]{6}{*}{15} & 0.1 & 0 & 379,450 & 6.05E-05 & 5.95E-04 \\
\hline & & 2 & 62,408 & 2.68E-04 & 2.64E-03 \\
\hline & & 4 & 50,527 & $3.22 \mathrm{E}-04$ & 3.17E-03 \\
\hline & 1 & 0 & 350,747 & 6.38E-05 & 6.27E-04 \\
\hline & & 2 & 41,544 & 3.87E-04 & 3.81E-03 \\
\hline & & 4 & 40,835 & 4.03E-04 & 3.96E-03 \\
\hline \multirow[t]{6}{*}{30} & 0.1 & 0 & 382,073 & $6.39 \mathrm{E}-05$ & $6.29 \mathrm{E}-04$ \\
\hline & & 2 & 35,757 & 5.54E-04 & 4.23E-03 \\
\hline & & 4 & 37,826 & 4.36E-04 & 4.29E-03 \\
\hline & 1 & 0 & 256,817 & 7.32E-05 & 7.19E-04 \\
\hline & & 2 & 15,107 & 1.07E-03 & 1.05E-02 \\
\hline & & 4 & 10,089 & 2.13E-03 & 2.06E-02 \\
\hline
\end{tabular}



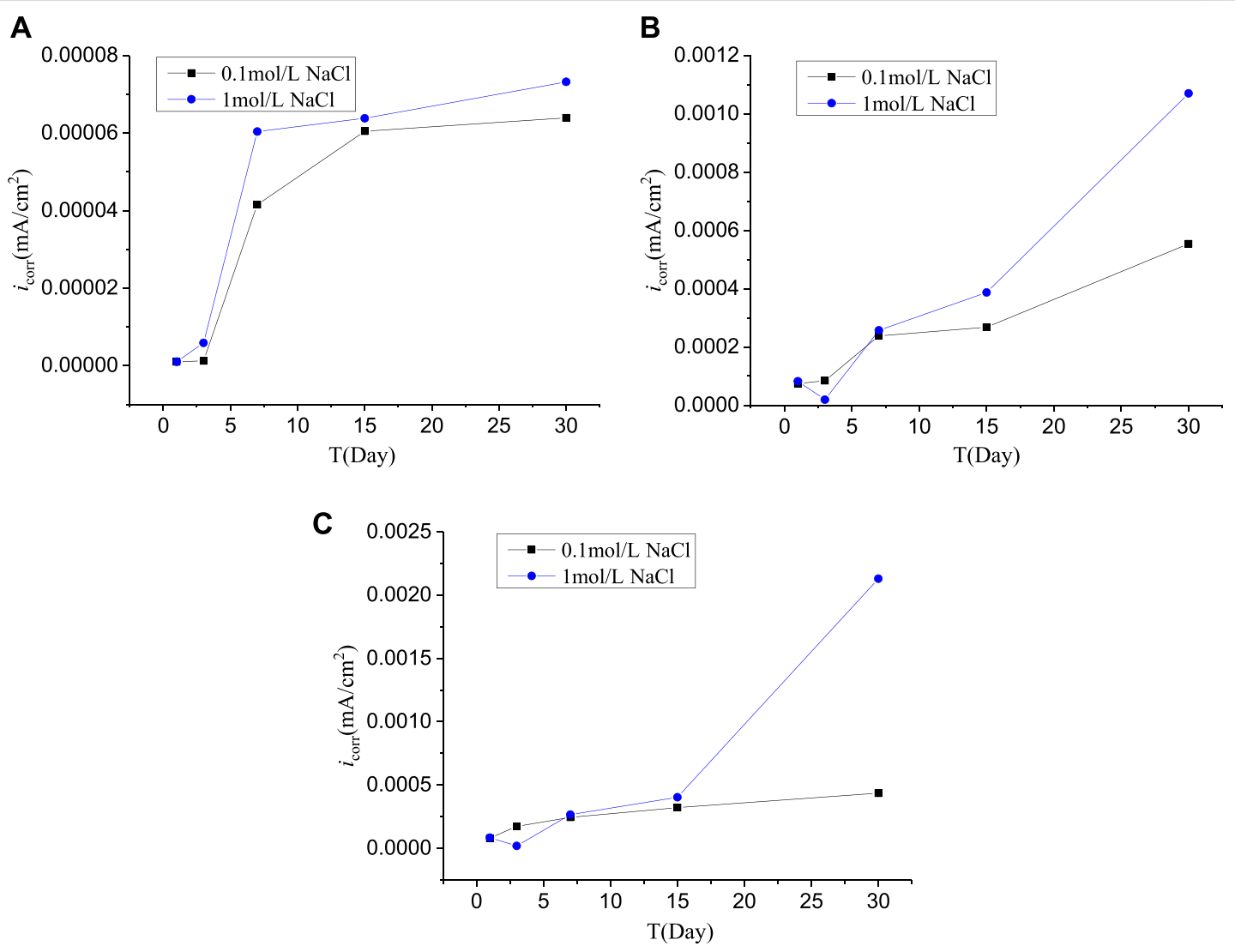

FIGURE 10 | Corrosion current density (A) S1 and S4; (B) S2 and S5; (C) S3 and S6.

It can be seen from Figures 6D,F that the equilibrium potential increases on the third day, and the polarization curve of the anode region changes faster than that of the cathode region. The reason may be that the corrosion reaction is under $\mathrm{O}_{2}$ diffusion control, which leads to a decrease in the corrosion current density, thus slowing down the anodic polarization rate and making the slope of the anodic polarization curve large.

\section{Polarization Resistance}

Thirty days of accelerated corrosion tests were carried out on coated steel specimens, and the experimental data of $1 \mathrm{st}, 3 \mathrm{rd}$, 7 th, 15th, and 30th days were recorded. After testing by electrochemical workstation, the polarization resistance of each steel bar is obtained by fitting, as shown in Figures 7, 8. Under the condition that the concentration of $\mathrm{NaCl}$ solution is $0.1 \mathrm{~mol} / \mathrm{L}$ and the surface coating is damaged $2 \mathrm{~cm}$, the anodic polarization resistance of the steel specimens at different times is $238,760,215,580,71,626,62,408$, and $35,757 \Omega \mathrm{cm}^{2}$. The polarization resistance of epoxy steel bars after accelerated corrosion has decreased much, indicating that the reaction rate of the steel bar surface has largely increased. As the corrosion continues, the polarization resistance becomes smaller and smaller, and the corrosion rate becomes higher and higher. By comparing the polarization resistance values of $1 \mathrm{~mol} / \mathrm{L} \mathrm{NaCl}$ solution, it can be seen that the duration of acceleration has a great influence on the corrosion effect, while the difference in polarization resistance values at the same time is small.

Compared with the $0.1 \mathrm{~mol} / \mathrm{L}$ concentration group, the polarization resistance value of concrete specimens after accelerated corrosion is reduced twice, indicating that the increase in $\mathrm{NaCl}$ solution concentration promotes corrosion. However, for $1 \mathrm{~mol} / \mathrm{L} \mathrm{NaCl}$ solution, there will be a sudden increase in polarization resistance on the third day, indicating that a passivation layer is produced on the steel bar at this time and then the passivation layer slowly disappears in a longer corrosion time.

By comparing the polarization resistance value of epoxy coating damaged 2 and $4 \mathrm{~cm}$, it can be seen that the polarization resistance value of steel bars damaged $4 \mathrm{~cm}$ is lower after the accelerated corrosion at the same time, indicating that the larger the coating damage, the faster will be the corrosion.

It is found that polarization resistance measured by the electrochemical workstation can be affected by potential deviation, and it is difficult to determine the error value. Therefore, the mean value data of the specimen with $1 \mathrm{~mol} / \mathrm{L}$ $\mathrm{NaCl}$ solution and $4-\mathrm{cm}$ damaged surface coat are selected as the 

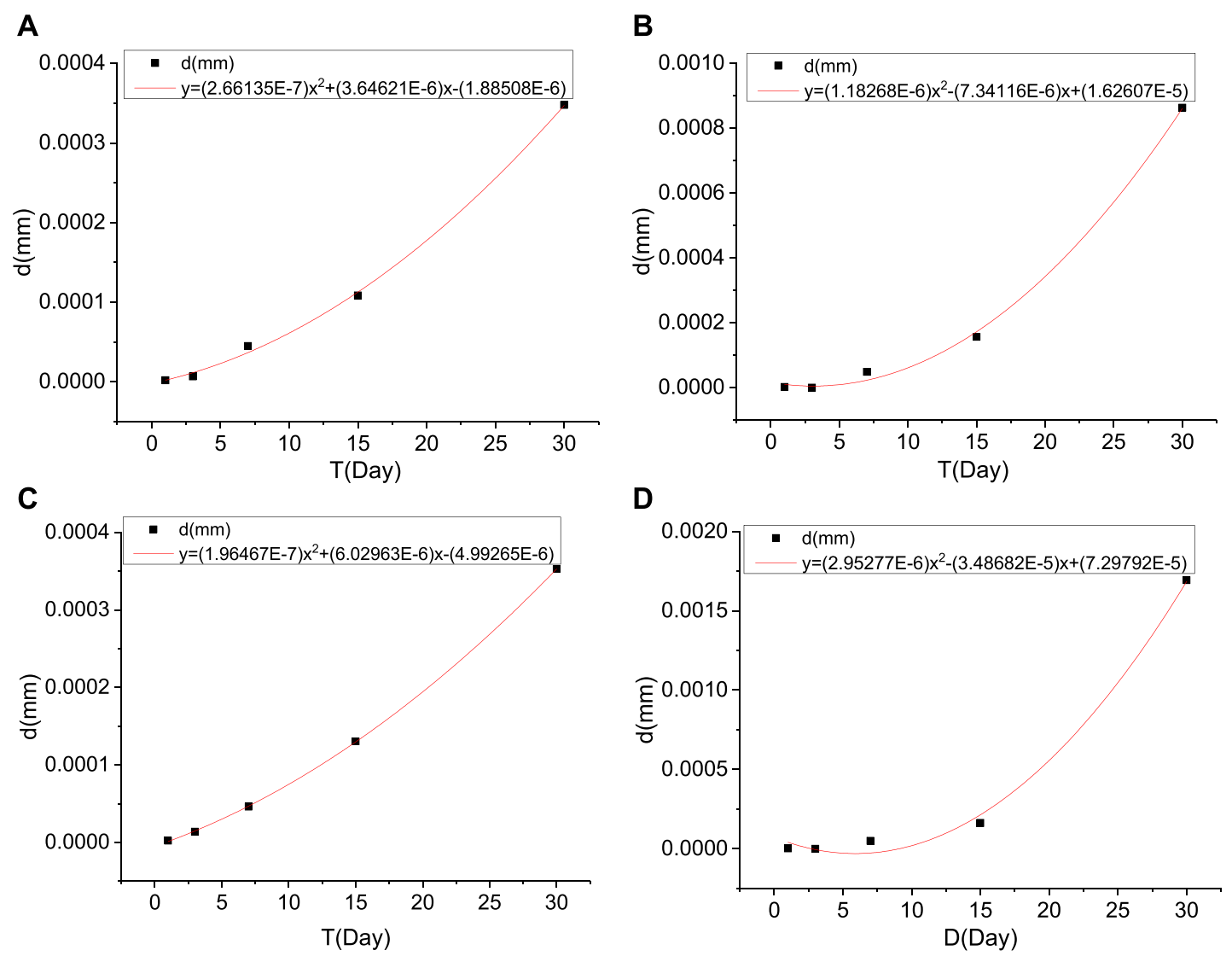

FIGURE 11 | Fitting curve of corrosion quantity (A) S2, (B) S5, (C) S3, and (D) S6.

research object. A section of polarization curve near $\mathrm{E}_{i=0}$ and $\mathrm{E}_{\text {corr }}$ is selected. First, the polarization curve is fitted, and then the tangent lines corresponding to $\mathrm{E}_{i=0}$ and $\mathrm{E}_{\mathrm{corr}}$ are drawn, respectively (Figure 9). It can be found that the slope (polarization resistance) is different. We suspect that actual polarization resistance may lie somewhere between these two curves.

It is difficult to calculate the exact value of the polarization resistance, and $R_{p}$ can be modified by the following formula to obtain a more realistic value:

$$
\begin{gathered}
R_{p}=\frac{R_{p}^{\prime}+R_{p}^{\prime \prime}}{2}, \\
R_{p}^{\prime}=\left(\frac{\partial \Delta E}{\partial I}\right)_{I=0, d E / d t \rightarrow 0}, \text { and } \\
R_{p}^{\prime \prime}=\left(\frac{\partial \Delta E}{\partial I}\right)_{E=E_{c o r r}, d E / d t \rightarrow 0} .
\end{gathered}
$$

The corrosion potential changes and corresponding polarization resistance values of epoxy steel bars at different scanning rates were measured and obtained and are given in Table 2. As the scanning speed decreases, the $R_{\rho}^{\prime} / R_{\rho}^{\prime \prime}$ value gradually approaches 1 , and when the scanning speed decreases to $0.10 \mathrm{mV} / \mathrm{s}, R_{\rho}^{\prime} / R_{\rho}^{\prime \prime}=0.90$ shows that the value of $R_{\rho}^{\prime}$ and $R_{\rho}^{\prime \prime}$ is very close.

\section{Corrosion Current Density}

The corrosion current and current density of each test block were recorded at days $1,3,7,15$, and 30 , and the current density diagram is drawn as shown in Figure 10. Compared with the initial corrosion current density of epoxy steel bars, the corrosion current density sometimes decreases after accelerated corrosion. This may be due to the passivation of the surface of steel bars during the electrification process of accelerated corrosion, leading to a decrease in the polarization area, so the reaction shows a slight decrease in the corrosion current density. By comparing the current density of the $2-\mathrm{cm}$ group and $4-\mathrm{cm}$ group corroded by epoxy steel bar coating in electrolytes with different concentrations, it can be seen that the difference in corrosion current density between the two groups becomes larger and larger after accelerated corrosion, indicating that the concentration of electrolyte solution plays a dominant role in the later stage of corrosion.

\section{Calculation of Corrosion Rate}

The corrosion rate is calculated according to the following equation: 


$$
M P Y=\frac{i_{\text {corr }} \times n \times 393.7 \times 365 \times 24 \times 3600}{\rho \times 96500},
$$

where MPY is the corrosion rate ( $\mathrm{mil} / \mathrm{a}), \mathrm{n}$ is the relative atomic mass, $\rho$ is the density of iron, and $i_{\text {corr }}$ is the corrosion current density, which is calculated from the measured corrosion current. Through fitting calculation, the corrosion rate of steel bars under different corrosion durations, electrolyte solution concentrations, and coating damage degrees can be obtained (Table 3).

Comparing these three groups of independent variables, it is found that in the case of coating damage, the accelerated corrosion duration is the primary influencing factor in this experiment. In contrast, the concentration of the solution has a greater effect on the corrosion rate than the damaged area of the coating in this experiment.

Through the analysis of experimental data, the corrosion curves of steel bars under different corrosion areas and $\mathrm{Cl}^{-}$ concentration are fitted, and then the numerical relationship between corrosion quantity and corrosion time is obtained by curve fitting (Figure 11).

As can be seen from Figure 11, after local corrosion of steel bars, the higher $\mathrm{Cl}^{-}$concentration, the will be the second derivative of the corrosion curve, indicating that when the coated steel bars are damaged, the $\mathrm{Cl}^{-}$concentration will have a greater influence on the long-term corrosion of steel bars. For the corrosion of 2- and 4-cm coatings, the corrosion rate of steel bars at $4 \mathrm{~cm}$ is almost twice as high as that at $2 \mathrm{~cm}$.

\section{CONCLUSION}

Based on the linear polarization theory principle, the electrochemical behavior of damaged epoxy-coated steel bars was analyzed using an accelerated corrosion test. The effects of the accelerated corrosion duration and electrolyte solution concentration on steel bar corrosion were analyzed through the check experiment. Finally, the following conclusions were drawn:

(1) When the epoxy coating is not damaged, the polarization curve is chaotic and there is no obvious electrochemical reaction characteristic. When the coating is damaged, the

\section{REFERENCES}

Atilgan, A., Yurdakul, Ş., Erdogdu, Y., and Güllüoğlu, M. T. (2018). DFT Simulation, Quantum Chemical Electronic Structure, Spectroscopic and Structure-Activity Investigations of 4-acetylpyridine. J. Mol. Struct. 1161, 55-65. doi:10.1016/j.molstruc.2018.01.080

Bautista, A., and González, J. A. (1996). Analysis of the Protective Efficiency of Galvanizing against Corrosion of Reinforcements Embedded in Chloride Contaminated concrete. Cement Concrete Res. 26 (2), 215-224. doi:10.1016/ 0008-8846(95)00215-4

Bellezze, T., Malavolta, M., Quaranta, A., Ruffini, N., and Roventi, G. (2006). Corrosion Behaviour in concrete of Three Differently Galvanized Steel Bars. Cement and Concrete Composites 28 (3), 246-255. doi:10.1016/ j.cemconcomp.2006.01.011 polarization curve has obvious change characteristics, through which the electrochemical reaction can be judged.

(2) With different solution concentrations, the development process of steel bar corrosion is different. In the early stage of the corrosion reaction, the slope of the anode polarization curve of the steel bar in $1 \mathrm{~mol} / \mathrm{L}$ electrolyte may be very large. The reason is the difficulty of electrochemical reaction caused by electrode passivation. In the long term, the development trend of corrosion is that the corrosion rate increases and the corrosion potential decreases.

(3) According to the polarization curve near the characteristic points, the true value of the polarization resistance needs to be corrected. The polarization resistance calculated by the modified formula is closer to the real value.

(4) According to the corrosion current density and the corrosion rate of steel bar, the higher the electrolyte solution concentration, the larger will be the damaged area of the coating and the faster will be the reaction. In comparison, the concentration of the electrolyte has a greater effect on corrosion.

\section{DATA AVAILABILITY STATEMENT}

The original contributions presented in the study are included in the article/Supplementary Material, and further inquiries can be directed to the corresponding authors.

\section{AUTHOR CONTRIBUTIONS}

HC worked on the conception and design of this study, and derived relevant formulas. WD analyzed the data and charted it. $\mathrm{ZL}$ and $\mathrm{ZZ}$ made important revisions to the manuscript. WG and YW participated in the writing and revision of the manuscript.

\section{FUNDING}

This work is supported by the major special science and technology project (2019B10076) of "Ningbo science and technology innovation 2025" and the scientific research project (2018035) of Zhejiang Provincial Department of Transportation.

Caldona, E. B., Wipf, D. O., and Smith, D. W. (2021). Characterization of a Tetrafunctional Epoxy-Amine Coating for Corrosion protection of Mild Steel. Prog. Org. Coat. 151, 106045. doi:10.1016/j.porgcoat.2020.106045

Clear, K. C., Hartt, W. H., McIntyre, J., and Lee, S. K. (1995). Performance of EpoxyCoated Reinforcing Steel in Highway Bridges. NCHRP Report 370. Washington, DC: National Cooperation Highway Research Program.

Darwin, A. B., and Scantlebury, J. D. (2002). Retarding of Corrosion Processes on Reinforcement Bar in concrete with an FBE Coating. Cement and Concrete Composites 24, 73-78. doi:10.1016/S0958-9465(01)00028-2

Elleithy, W. M., Sharif, A. M., Al-Amoudi, O. S. B., Maslehuddin, M., and Kalam Azad, A. (1998). Effect of Holidays and Surface Damage to FBEC on Reinforcement Corrosion. Construction Building Mater. 12 (4), 185-193. doi:10.1016/S0950-0618(98)00004-X

Erdoğdu, S., Bremner, T. W., and Kondratova, I. L. (2001). Accelerated Testing of plain and Epoxy Coated Reinforcement in Simulated Seawater and Chloride 
Solutions. Cement Concrete Res. 31, 861-867. doi:10.1016/S0008-8846(01) 00487-2

Feng, W., Tarakbay, A., Ali Memon, S., Tang, W., and Cui, H. (2021). Methods of Accelerating Chloride-Induced Corrosion in Steel-Reinforced concrete: a Comparative Review. Construction Building Mater. 289 (2), 123165. doi:10.1016/j.conbuildmat.2021.123165

Gowripalan, N., and Mohamed, H. M. (1998). Chloride-ion Induced Corrosion of Galvanized and Ordinary Steel Reinforcement in High-Performance concrete. Cement Concrete Res. 28 (8), 1119-1131. doi:10.1016/S0008-8846(98)00090-8

Grundmeier, G., Schmidt, W., and Stratmann, M. (2000). Corrosion protection by Organic Coatings: Electrochemical Mechanism and Novel Methods of Investigation. Electrochimica Acta 45 (15-16), 2515-2533. doi:10.1016/ S0013-4686(00)00348-0

Guan, X. (2007). The Study and Design on the Eclectrochemical Power Measurement Workstatio Based on Dsp (Harbin: Harbin University of Science and Technology). MA thesis.

Kim, K.-H. E., and Andrawes, B. (2019). Exploratory Study on Bond Behavior of Textured Epoxy-Coated Reinforcing Bars. J. Mater. Civ. Eng. 31 (8), 04019151. doi:10.1061/(ASCE)MT.1943-5533.0002799

Kobayashi, K., and Takewaka, K. (1984). Experimental Studies on Epoxy Coated Reinforcing Steel for Corrosion protection. Int. J. Cement Composites Lightweight Concrete 6 (2), 99-116. doi:10.1016/02625075(84)90039-3

Li, Q., Jin, X., Yan, D., Fu, C., and Xu, J. (2021). Study of Wiring Method on Accelerated Corrosion of Steel Bars in concrete. Construction Building Mater. 269 (3), 121286. doi:10.1016/j.conbuildmat.2020.121286

Manning, D. G. (1996). Corrosion Performance of Epoxy-Coated Reinforcing Steel: North American Experience. Construction Building Mater. 10 (5), 349-365. doi:10.1016/0950-0618(95)00028-3

Montes, P., Bremner, T. W., and Kondratova, I. (2004). Eighteen-year Performance of Epoxy-Coated Rebar in a Tunnel Structure Subjected to a Very Aggressive Chloride-Contaminated Environment. Corrosion 60 (10), 974-981. doi:10.5006/1.3287832

Nguyen, T., and Martin, J. W. (2004). Modes and Mechanisms for the Degradation of Fusion-Bonded Epoxy-Coated Steel in a marine concrete Environment. J. Coat. Technol. Res. 1 (2), 81-92. doi:10.1007/s11998-004-0002-6

Pyc', W. A. (1998). Field Performance of Epoxy-Coated Reinforcing Steel in Virginia Bridge Decks (Virginia: Faculty of the Virginia Polytechnic Institute and State University). Ph.D. thesis.

Selvaraj, R., Selvaraj, M., and Iyer, S. V. K. (2009). Studies on the Evaluation of the Performance of Organic Coatings Used for the Prevention of Corrosion of Steel Rebars in concrete Structures. Prog. Org. Coat. 64 (4), 454-459. doi:10.1016/ j.porgcoat.2008.08.005

Shang, H., Shao, S., and Wang, W. (2021). Bond Behavior between Graphene Modified Epoxy Coated Steel Bars and concrete. J. Building Eng. 42, 102481. doi:10.1016/j.jobe.2021.102481

Singh, D. D. N., and Ghosh, R. (2005). Unexpected Deterioration of FusionBonded Epoxy-Coated Rebars Embedded in Chloride-Contaminated Concrete Environments. Corrosion 61 (8), 815-829. doi:10.5006/1.3278216

Smith, J. L., and Virmani, Y. P. (1996). Performance of Epoxy-Coated Steel Bars in Bridge Decks. Public Roads 60 (2), 6-12.
Stratmann, M., Feser, R., and Leng, A. (1994). Corrosion protection by Organic Films. Electrochimica Acta 39 (8-9), 1207-1214. doi:10.1016/0013-4686(94) E0038-2

Venkatesan, P., Palaniswamy, N., and Rajagopal, K. (2006). Corrosion Performance of Coated Reinforcing Bars Embedded in concrete and Exposed to Natural marine Environment. Prog. Org. Coat. 56 (1), 8-12. doi:10.1016/j.porgcoat.2006.01.011

Wang, X.-H., Chen, B., Gao, Y., Wang, J., and Gao, L. (2015). Influence of External Loading and Loading Type on Corrosion Behavior of RC Beams with EpoxyCoated Reinforcements. Construction Building Mater. 93 (15), 746-765. doi:10.1016/j.conbuildmat.2015.05.101

Wang, X.-H., and Gao, Y. (2016). Corrosion Behavior of Epoxy-Coated Reinforced Bars in RC Test Specimens Subjected to Pre-exposure Loading and WettingDrying Cycles. Construction Building Mater. 119, 185-205. doi:10.1016/ j.conbuildmat.2016.05.066

Weyers, R. E., Pyc, W., Zemajtis, J., Liu, Y., Mokarem, D., and Sprinkel, M. M. (1997). Field Investigation of Corrosion-protection Performance of Bridge Decks Constructed with Epoxy-Coated Reinforcing Steel in Virginia. Transportation Res. Rec. 1597, 82-90. doi:10.3141/1597-11

Wu, F. (2016). Study on the Bond-Slip Constitutive Relation between Corroded Steel Bar and concrete under the Coupling Action of Load and Environment (Chongqing: Chongqing Jiaotong University). MA thesis.

Zhang, Z., Jung, D., and Andrawes, B. (2020). Evaluation of Surface Roughness and Bond-Slip Behavior of New Textured Epoxy-Coated Reinforcing Bars. Construction Building Mater. 262 (2), 120762. doi:10.1016/ j.conbuildmat.2020.120762

Zhao, Q., Zhang, D., Zhao, X.-L., and Sharma, S. (2021). Modelling Damage Evolution of Carbon Fiber-Reinforced Epoxy Polymer Composites in Seawater Sea Sand concrete Environment. Composites Sci. Techn. 215, 108961. doi:10.1016/j.compscitech.2021.108961

Conflict of Interest: WD was employed by the China Highway Engineering Consulting Corporation Road and Bridge Design and Research Institute Branch.

The remaining authors declare that the research was conducted in the absence of any commercial or financial relationships that could be construed as a potential conflict of interest.

Publisher's Note: All claims expressed in this article are solely those of the authors and do not necessarily represent those of their affiliated organizations, or those of the publisher, the editors, and the reviewers. Any product that may be evaluated in this article, or claim that may be made by its manufacturer, is not guaranteed or endorsed by the publisher.

Copyright (C) 2022 Cao, Lyu, Dong, Zhao, Gan and Wang. This is an open-access article distributed under the terms of the Creative Commons Attribution License (CC $B Y)$. The use, distribution or reproduction in other forums is permitted, provided the original author(s) and the copyright owner(s) are credited and that the original publication in this journal is cited, in accordance with accepted academic practice. No use, distribution or reproduction is permitted which does not comply with these terms. 